\title{
UNA BÚSQUEDA QUE SE BIFURCA
}

\author{
(Esquema de trabajo) \\ Es duro estar enamorado de las personas que no se deben \\ Donna Tartt, El jilguero \\ Marcos Yauri Montero \\ Universidad Ricardo Palma \\ marcos.yaurim@urp.pe
}

\section{RESUMEN}

Este artículo es un intento de aproximación al problema de la integración nacional a partir de las ideas de la producción que diversos especialistas han escrito en la primera década del siglo XXI. Es una incitación a superar los enfoques conservadores que dan la impresión de seguir manteniendo vigentes los contrastes y diferencias que hacen del Perú un país troceado.

\section{PALABRAS CLAVE}

Integración/ Nacional/ Conservador/ Contrastes/ Diferencias/ Troceado

\section{ABSTRACT}

This article is an approach to the integration problem, since the production that several specialists have written during the first decade of twenty one century. It's an intention to overcome the traditions, that wants to keep the differences that makes Perú a broken country.

\section{KEY WORDS}

National/ Integration/ Tradition/ Differences/ Broken 
Nuestro país, reconocido como multinacional, con una sociedad multirracial, multicultural, multilingüe, desde hace tiempo constituye la pasión de estudiosos de diversas tiendas culturales, políticas, literarias y aún gastronómicas. En otras palabras, nuestra condición de país troceado es un tema sumamente atractivo.

Hoy en día, en la primera década y media del s. XXI esa pasión tiende a intensificarse. La actitud no es fortuita debido a que el peso de nuestra realidad es impactante. Esta más el peso del pasado son fuerzas que la motivan y sustentan. En este escenario surgen muchas interrogantes: ¿No han servido de nada los esfuerzos por alcanzar una integración? ¿Han sido realizados esos esfuerzos? ¿De haber existido esos proyectos por qué el fracaso? ¿Continúan influyendo determinadas ideas, políticas, actitudes que desean que nada cambie?

\section{MUCHOS AUTORES. MUCHOS LIBROS}

El Perú como tema es un tópico de larga data. La historia del pensamiento peruano nos deja vislumbrar los aportes iniciales en la obra del inca Garcilaso de la Vega, Felipe Huamán Poma de Ayala. Prosigue en las elucubraciones de José de la Riva Agüero primero, después en los libros de Manuel Gonzáles Prada, Luis E. Valcárcel, Víctor Andrés Belaunde, Jorge Basadre, José Carlos Mariátegui. No es nuestro propósito poner en el tapiz las ideas de cada uno de estos pensadores que giran en torno del tema de la integración de nuestro país, como tampoco de los nuevos y últimos. Esta sería una dura labor que merecería un tiempo largo. Si de alguna manera vamos a tocar el tópico, este será abordado desde una perspectiva general, apuntando hacia el espacio de la literatura.

En la primera década y media del s. XXI hay una profusa producción de libros con el tópico del Perú. Ninguno con ambición totalizadora. Cada autor ha estudiado un fragmento de su realidad múltiple. Los "temidos" estudios culturales han tenido mucho que ver en esta forma de amar al país, acercándose lo más posible a la cultura popular en sus variadas expresiones, desde el leguaje, la literatura, las artes, el pensamiento, los acontecimientos históricos no tocados por la historia oficial, etc. Como una muestra de esta variada y numerosa producción mencionaremos algunos títulos que hemos llegado a conocer directamente, teniendo siempre presente de que más allá de esta relación hay otros estudios de los que tenemos referencias a través de la lectura de otros estudiosos.

En orden correlativo esos trabajos son: Antología. Cincuenta años de narrativa andina. Desde los años 50 hasta el presente (Lima, 2004), del norteamericano Mark Cox; De Doña Bárbara al neoliberalismo: Escritura y modernidad en América Latina (Lima, 2006) de José Castro Urioste; Perú y Europa: 
dos casos de historias conectadas. (Siglos XVI y XVIII) (Lima, 2009) de Fernando Rosas Moscoso; Indios, dios, runa. Antología poética del profeta del fuego, (Lima, 2010), un estudio, selección y notas de Gonzalo Espino Relucé en relación con la producción poética de Efraín Miranda; La literatura oral o la literatura de tradición oral (Lima, 2010) del mismo autor; Escritura quechua en el Perú (Lima, 2011) de Julio Noriega Bernuy; Racionalidades en conflicto. Cosmovisión andina (y violencia política) en Rosa Cuchillo de Óscar Colchado (Lima, 2011) de Edith Pérez Orozco; Todas las sangres en debate. Científicos sociales versus criticos literarios (Lima, 2011) de Dorian Espezúa Salmón; Indagaciones heterogéneas. Estudios sobre literatura y cultura (Lima, 2012) de Carlos García Bedoya M.; ;Soi indio! Estudios sobre la poesía de Efrain Miranda (Lima, 2013) de Gonzalo Espino Relucé, Mauro Mamani y Guissela Morvell, (editores) que contiene artículos de más de 20 estudiosos; Literaturas regionales (Lima, 2013) de Jorge Terán Morvelli; Elegía Apu Inca Atawalpaman (Lima, 2014), de Odi Gonzáles; Ama wakashpalla (Lima, 2014) de Edmundo Bendezú Aybar; Poéticas afroindoamericanas (Lima, 2014) de Carolina Ortiz Fernández; Augusto Higa (Lima, 2015) de Paul Asto Valdez y Edith Pérez Orozco, (editores).; Micronegocios vs. Megamercados: Otros sentidos de identidad, distinción y consumo en los microempresarios de Lima Norte (Lima, 2014), de Pedro Jacinto Pazo; Narrativa de la víctima (Lima, 2015) de Douglas Rubio Bautista.

El contenido de estos libros revela la honda preocupación de los intelectuales peruanos por conocer las variadas aristas de nuestra realidad cultural, cada una enfocada desde una perspectiva dictada por su especialidad a cada uno de los autores. Su lectura conduce a determinar algunas características:

1. Intensificación de los estudios teóricos en torno a la literatura de tradición oral.

2. Aplicación de teorías y metodologías en el estudio de las literaturas orales del ámbito quechua y su ampliación a las literaturas amazónicas y afroperuanas.

3. Un gran interés por el quechua, su defensa, preservación y su papel de repositorio de la literatura oral tradicional y de la que se sigue creando en la actualidad.

4. Descubrimiento de los sujetos de la narrativa urbana y popular.

5. Incitación a la relectura de las crónicas del s. XVII: Nueva crónica y buen gobierno de Felipe Huamán Poma de Ayala, Dioses y hombres de Huarochirí de Francisco de Ávila, así como de Los comentarios reales, de Garcilaso de la Vega con incidencia en la vida y personalidad de 
su autor. Asimismo incitación al estudio de la crónica: Representación verdadera del P. Francisco Antonio Garro (s. XVIII)

6. Propuesta para relacionar el estudio de la Historia del Perú con la historia de Europa en un valioso intento de establecer conexiones para una mejor comprensión de los acontecimientos.

7. Retorno de los regionalismos.

8. Interés por los estudios monográficos de determinadas obras de autores, en su mayoría de origen andino: quechua o aymara y de algunas minorías étnicas de origen japonés o afroperuano.

\section{REFORMA AGRARIA. DESBORDE POPULAR}

La reforma agraria impuesta por el gobierno del general Juan Velasco Alvarado en 1970, luego el desborde popular de los años 60 que se acrecentó a partir de los 80 desatando una oleada de migraciones a nivel nacional, son factores internos que han transformado al Perú. Los teóricos de la reforma agraria no han probado que la tierra es para quien la trabaja. Este aforismo que antes de la reforma asumió la metáfora de la redención no se ha cumplido. La idea de que el indígena y campesino convertidos en propietarios de la tierra se quedarían en su querencia donde crearían los llamados «Polos de desarrollo» que fue el sueño de los reformistas se convirtió en derrumbe. Indígenas y campesinos beneficiados abandonaron su lugar nativo y convertidos en aluvión (lloclla) humano se vaciaron a las grandes ciudades: capitales de departamento o las ubicadas en la costa y de preferencia Lima, la tierra prometida. A este fenómeno el maestro José Matos Mar llamó el Desborde popular cuya consecuencia mayúscula es el nacimiento de una nueva sociedad nacional. Desborde popular, es decir un fenómeno consumado por el Perú olvidado, rural y pobre que resolvió migrar a la costa para modernizarse sin el apoyo del gobierno, de las ideologías y políticas. Ha sido una revolución social incruenta, lejanamente iniciada en los años 40, antes de la proclama de los zorros y de la carta dirigida a los falsos doctores del corazón de Lima desde los arenales desérticos y que asimismo fue vislumbrada por Julio C.Tello y Luis E. Valcárcel desde los Andes tempestuosos.

El desborde popular no ha borrado la imagen del Perú fracturado. Nuestro país sigue siendo un ente binario: el Uno y el Otro, el Perú Oficial y el Otro Perú. El Perú sigue siendo múltiple, políticamente, tributariamente, cultural, racial, lingüísticamente, etc. El desborde popular ha dado origen al cambio de la sociedad nacional, ha contribuido a visibilizar mejor nuestra multirracialidad, multiculturalidad, informalidad, etc. Los especialistas en las ciencias sociales ahora conocen mejor nuestras características, que no son del todo nuevas, sino que las venimos arrastrando desde siglos. Lo novedoso es que dichos fenómenos que se 
han intensificado bajo el peso de la globalización y la mundialización ${ }^{1}$, hoy, debido a la fragilidad de nuestro país han originado otros fenómenos sociales, económicos, culturales, políticos, etc. que afectan la tradición, la cultura, las costumbres, la seguridad, al Estado, en general a la vida y que al masificarse son fuerzas que transgreden el control y la formalidad. Estos son los espacios privilegiados de nuestros estudiosos y analistas. Se colige, entonces, que existe en estos estudios un vacío, una distancia histórica entre nuestro presente construido por el desborde popular y la memoria del pasado. Es esta memoria que debe merecer atención para conocer al Perú hirviente de nuestros días, donde las masas rebasan los bordes y el Estado no funciona. Fenómeno difícil de ser profundizado y explicado porque el pasado pesa de modo aplastante en nuestra realidad actual y obnubila nuestra mirada según cómo y de dónde se mire ya sea desde las ciencias sociales, la literatura, las artes, la cultura popular, las ideologías, etc.

La memoria de los vencidos sobrevive a todas las formas de la muerte ${ }^{2}$. En el caso del Perú esta memoria abarca 500 años de nuestra historia. Quinientos años que se reparten en 300 que pertenecen a la vida colonial y 200 a la vida republicana. Quinientos años de vida que le fue negada a la gran mayoría de la población peruana. El desborde popular, entonces tiene doble rostro: primero, la recuperación de esa vida perdida que al empezar a ser vivida por los negados de ayer, está forzando a la renovación de las estructuras de un Estado envejecido; segundo, el deseo del retorno de una forma de existencia milenaria del Perú como patria antigua ${ }^{3}$.

\section{INKARRÍ}

Este antiguo mito de carácter panandino irrumpió en las especulaciones sociales y literarias a partir de 1970. Es un producto del otro Perú de cultura oral que

1 "La globalización suele ser entendida como un proceso de homogeneización planetaria. En cambio, conviene retomar aquí una importante distinción introducida por el brasileño Renato Ortiz. Para Ortiz, la globalización es una categoría aplicable a los ámbitos de la economía y la tecnología y supone en esos niveles procesos de homogeneización planetaria. En cambio, para el ámbito de la cultura prefiere hablar de mundialización, pues a pesar de tendencias uniformizadoras, sobre todo a nivel de las industrias culturales, el panorama planetario se caracteriza por la coexistencia conflictiva de lo diverso". En: Indagaciones heterogéneas. Estudios sobre literatura y cultura, García Bedoya, Carlos, Lima, Grupo Pakarina, 2012, pp. 31, 32

2 "...la memoria de los vencidos también sobrevive a todas las formas de la muerte" (Tyras, 2005) en Françoise Aubes: "La novela de Atusparia o cómo la memoria de las luchas andinas ingresa a la literatura": Lhymen. Cultura y Literatura, Año VI, Lima, 2007, No. 4, p. 121.

3 Metáfora usada por Luis E. Valcárcel en su libro: Ruta cultural del Perú. 
como un rizoma deleuziano ha viajado y aún continúa viajando por los bordes, jamás por el centro oficial y por tanto es marginal, periférico ${ }^{4}$. Lo han analizado connotados especialistas: Ortiz Rescaniere, Franklin Pease, Marco Curatola y otros. Una síntesis demuestra que Inkarrí es hijo de un dios poderoso del cielo, masculino y fertilizador y de una diosa intermedia y fertilizada. De este modo tiene poderes de organizador y armonizador entre principios contrarios. Establece el orden social y natural y crea la agricultura, el uso del agua, además de ser constructor. Representa la confrontación entre él y un poder antagónico que es el caos, la anticultura, la pobreza, el hambre, la oscuridad de los que Pizarro o el español son sus representantes. Esta confrontación se da en un escenario donde el tiempo se divide en un pasado que corresponde a Inkarrí: tiempo de luz y orden, y el presente que pertenece al enemigo extranjero. La lucha entre los dos produce la muerte de Inkarrí y el reinado del enemigo; en este tiempo se extienden las tinieblas, retornan el salvajismo, la pobreza, el caos. Esta catástrofe es el Pachacuti que según Curatola es: «la problemática de la existencia misma del universo y del hombre». De su cabeza sepultada en un lugar desconocido está creciendo su cuerpo y cuando esté completo retornará y se producirá el reordenamiento del mundo que se puso al revés. Los dominados recuperarán su lugar, su orden social y cultural, etc. Inkarrí, entonces representaría a un mesías andino. Esta fe originó la idea de la utopía andina que apuntó al retorno del tiempo ordenado, armónico, feliz. Las huacas retornarían ${ }^{5}$

El filósofo Ernest Cassirer asevera que el hombre antes de hacer historia hace mito. En los pueblos ágrafos de los tiempos primitivos el mito, a través de la oralidad fue nómada hasta que la escritura lo archivó. Esto no sucedió en la cultura autóctona peruana porque fue eminentemente oral.

¿Se puede pensar que el relato de Inkarrí fue el presagio del desborde

4 La categoría de Rizoma introducida por Gilles Deleuze y F. Guattari en el campo filosófico tiene su representación en la grama, el crab-grass que en su recorrido se ramifica e interrumpe, erige recomienzos y surgimientos múltiples sin fin, forman rizomas causa de nuevas ramificaciones y conexión sin término debido a que tiene formas de desterritorialización y reterritorialización, de heterogeneidad y conexión, etc. Según esta idea: "No hay lengua madre, sino toma del poder de una lengua dominante en una multiplicidad política... "En la lengua siempre se pueden efectuar descomposiciones estructurales internas: es prácticamente lo mismo que buscar raíces" Deleuze, G, Guattari, F, Rizoma. Introducción, 2000 Valencia Pretextos, p.18

5 Consultar: El retorno de las huacas, Sociedad Peruana de Psicoanálisis, Lima, 1990-. Contiene estudios de Rafael Varon Gabai, Sara Castro Klarén, Moises Lemlij, Alberto Péndola, María Rostworowski, Max Hernández, Luis Millones. 
popular? Sea cual fuere la respuesta lo cierto es que ese evento ha cambiado al Perú. Ha puesto fin a la estructura tradicional social y económica. El contingente provinciano de migrantes vencedor de dificultades, hoy representa al Perú emprendedor en crecimiento económico. Ha posibilitado la descentralización, el liderazgo popular y provinciano. El Perú rural de 1940 (64\%) a partir del 2010 es urbano (80\%). En 1940 el $65 \%$ de la población vivía en la sierra, a partir del 2007 esa población ha descendido al $32 \%$. Ha cambiado la estructura social de grupo alto, medio y bajo; hoy la competitividad y la capacidad de compra han creado una nueva estratigrafía; los grupos son: A (ricos), B (pudientes), C (medios), D (bajos), $\mathrm{E}$ (pobres). Ha cambiado drásticamente el estilo de vida de Lima; ahora esta ciudad es la más provinciana del país, los migrantes convertidos en los nuevos limeños se han occidentalizado y modernizado.

Al cambio del país causado por el desborde popular (estudiado por José Matos Mar), el economista peruano Hernando de Soto añade otro factor: la derrota de Sendero Luminoso por los campesinos. Dice: «Entre 1990 y 2012 la nueva clase media peruana creció cuatro veces más rápido que la del resto de América Latina. ¿Por qué? Porque es un movimiento emancipador que hace medio siglo está en metamorfosis: De clase baja a migrantes, y después a informales, sector del cual ha emergido la nueva clase media y la minería informal $\rangle^{6}$ Según Hernando de Soto los campesinos condenados por el Estado y la sociedad dominante a una existencia ilegal y por tanto marginal, desde 1960 hasta 1988 y 1992, no pudieron derrotar a Sendero Luminoso porque por ser informales el estado peruano rehusó apoyarlos. Pero cuando percibió que Sendero Luminoso podía ganarle la guerra, decidido a contar con su poder tomó medidas para que esos ilegales accedieran a la legalidad, situación que propició los cambios en el escenario nacional: «Todo cambió cuando los políticos se percataron de que las mayorías se identificaban con los cambios. ${ }^{7}$

6 «La nueva clase media peruana nació en Ayacucho». El Comercio- A22 País, Lima, 30 de marzo del 2014, pp. 22-23

7 La marginalidad del indígena y campesino causada por la mentalidad poscolonial de la política, del Estado y de la sociedad peruana, también se ha debido al abusivo uso de la categoría de la alteridad con tendencia conservadora teñida de cierto romanticismo que privilegiaba lo silvestre, que se practicó en la academia y en el escenario cultural, evento que desafortunadamente continúa. Hernando de Soto en el artículo mencionado en relación a los acontecimientos de Uchuraccay escribe: «Lo que sí sabemos, porque los hemos seguido, es que luego de tres décadas los habitantes de Uchuraccay han probado que de primitivos no tienen nada. Varios han ascendido a la clase media y hoy son empresarios del comercio y del transporte en Huanta, de metalmecánica en Tambo, mayoristas de granos en Huaychao, dueños de radios en Lima, funcionarios públicos en Ayacucho, profesores en ciencias sociales aquí y allá. Esta gestación de la clase media 


\section{EL DESEMBALSE}

Los cambios que se han producido en el Perú parecen darle la razón a la interpretación del mito. El Perú invisible representado novelísticamente por Manuel Scorza con el personaje Garabombo ahora es visible. En los años iniciales del gobierno militar que tras la reforma agraria y la nacionalización del petróleo las ideas del cambio se tornaron febriles, la cultura del Perú olvidado se hizo presente con su cuerpo o sus símbolos. Bástenos un ejemplo: el sombrero con el que aparece en la iconografía Túpac Amaru II, se convirtió en el logotipo de muchas empresas y supermercados. El pintor o diseñador lo estilizó bajo el influjo del nuevo arte de los poster. Los hippies mestizos o criollos del Perú de ese tiempo, los turistas extranjeros que visitaban el Perú atraídos por la novedad de los cambios, añadieron a su atuendo ese sombrero tupamaro para resaltar su imagen con cabellos largos, sandalias y blue jeans con apariencia de excesivamente usados. En ese gesto, quizás sin que mediara una decisión, confluyeron la rebeldía indígena y mestiza que aspiraba al cambio social y el serio cuestionamiento que hizo a la sociedad de consumo mundial la juventud de las universidades de París en el movimiento de mayo de 1968. Las artesanías ayacuchana, cusqueña y de otros lugares del país empezaron a difundirse en mercados, exposiciones y ferias. Joaquín López Antay fue galardonado con un Premio que le otorgó el Instituto Nacional de Cultura, acontecimiento que para la mentalidad conservadora limeña significó un desacierto herético y fomentó un gran escándalo

En 1971, en Cajamarca, se llevó a cabo el Segundo Encuentro de Narradores Peruanos. En el prólogo al libro publicado en 1988 rescatando los testimonios y lecturas, de dicho evento, Antonio Cornejo Polar, escribió: Pesó mucho en Cajamarca el contexto político-social de esos años. Hay que recordar que por

también se dio en el resto del país: los llamados primitivos integran los sectores sociales que más han crecido en los últimos años» Íbid. p. A22.

El Informe de la Comisión Investigadora de los sucesos de Uchuraccay, que minimizó a los indígenas iquichanos al presentarlos como paradigma de una comunidad andina de vida aislada, violenta, casi exótica, en suma como el Otro y subalterno, es recusado por muchos intelectuales, entre ellos por el antropólogo peruano Renato Merino Solari (UNMSM).La episteme que esgrimieron los especialistas de esa comisión estuvo en boga en la producción académica de las décadas de 1970 y 1980; y por otra parte: «...evidencia el maridaje entre la producción del conocimiento y la política. En otros términos, dicho texto representa un espacio que demuestra la permanente articulación del saber con el poder» «Lo que Dios unió que lo desuna el hombre. La representación como vínculo primordial entre el poder y el conocimiento» Lhymen, Cultura y Literatura, No 4, Lima, junio 2007, pp. 27,46. 
entonces todavía era legítimo discutir el sentido de las "reformas estructurales" del gobierno de Velasco y hasta poner otras, incluso más audaces y más ligadas al campo cultural: Que después todo se hizo añicos, comenzando por la voluntad reformista de los militares, no quita mérito a quienes querían forzar definiciones políticas más radicales, ni sagacidad a quienes veían el proceso desde una perspectiva abiertamente escéptica y crítica. En todo caso, confirmando la vieja tradición que vincula al intelectual peruano a los conflictos y esperanzas nacionales, los escritores que se reunieron en Cajamarca reafirmaron, cada cual a su manera, su compromiso esencial con el destino colectivo del país. ${ }^{8}$ Hubo un espacio importante en este Encuentro: la propuesta para desbordar los límites de la narrativa peruana en castellano y reivindicar la riqueza de la narrativa oral en lenguas nativas. ${ }^{9}$

El desborde popular fue un desembalse. Quinientos años de vida embalsada en un espacio periférico, empujada por la postergación y la pobreza se precipitó a oleadas. Esas masas en movimiento en busca de un lugar donde encontrar medios de supervivencia y seguridad al abandonar su cuna no cargó su tierra pero sí su lengua, sus tradiciones, sus costumbres, sus modos de pensar. Este patrimonio cambió la imagen urbana o semiurbana, según los casos del país, espacios que habían empezado a ser alterados por la modernidad y la globalización. Fenómeno que no puede ser abarcado en un pequeño artículo como el presente, pero sí comprendido mediante una estrategia, por ejemplo con el uso del apotegma del historiador norteamericano James Lockhart: Existen patrones generales en un nivel local y muchos patrones importantes observables solo en el nivel local. Tomaremos como muestra la capital del departamento de Ancash, Huaraz, vinculada a las ciudades del Callejón de Huaylas. Destruida en mayo de 1970 por un terremoto Huaraz se convirtió en un espacio donde el gobierno militar encontró oportunidad para demostrar su política social en favor de los olvidados, e inclusive para intentar la experiencia de una reforma urbana con la expropiación de los terrenos que ocuparon las casas destruidas, eventos que dieron lugar a una interpretación lindante con el mito: la destrucción de Huaraz era el fin de una época

8 Segundo encuentro de narradores peruanos, 1988, Instituto Nacional de Cultura de Cajamarca, p.s/n.

9 El maestro Antonio Cornejo Polar escribió: "Debe destacarse, como un mérito de los organizadores, la ampliación del temario del Encuentro con la inclusión de debates sobre el teatro (que resultó uno de los más interesantes) y sobre el folclore. Este último implicó una muy saludable ruptura del enclaustramiento de la narración peruana dentro de los límites de la escritura en español y una audaz y válida propuesta destinada a reivindicar la inmensa riqueza de nuestra narrativa oral. A largo plazo, tal vez esta sea la lección más duradera del Encuentro de Cajamarca" Íbid. p.s/n. La propuesta fue hecha por Francisco Izquierdo Ríos y Marcos Yauri Montero 
y el alumbramiento de una nueva. Lo real fue que después del terremoto el espacio huaracino fue un lugar abierto adonde acudieron bandadas de migrantes de las diferentes regiones del país. ¿Acaso la infortunada ciudad se convirtió en una tierra prometida como Chimbote, próspera con la industria del acero y de la harina de pescado? La verdad es que a ese Huaraz que era solo montañas de escombros se precipitó un aluvión humano de migrantes. De bilingüe devino en multilingüístico, al castellano y quechua locales se sumaron las variantes del quechua del centro y del sur del país y los variados aimaras puneños. A la tradición, cultura, costumbres, gastronomía, etc. de la localidad se añadieron las de los migrantes. Socialmente, las viejas clases medias huarasinas en su mayoría había muerto, los sobrevivientes se fueron. Quienes migraron a Huaraz fueron campesinos o de extracción campesina de diferentes zonas del país o habitantes populares de los asentamientos costeños y limeños, contingente al que se agregó el campesinado huarasino y provincial del departamento. Cambió el paisaje humano y también la cultura. La otrora Huaraz urbana, mestiza, occidentalizada, pacífica, atildada y variopinta, empalideció, sus niveles sociales y culturales sucumbieron. Nuevas costumbres surgieron, nuevos festivales y rituales, nuevas músicas y danzas, nuevas formas de consumo. Los nuevos habitantes formaron sus clubes, cada uno con su calendario de festividades y conmemoraciones. El Huaraz de antes del terremoto convertido en minoría se replegó en ese archipiélago de culturas.

Huaraz al promediar la segunda mitad del s. XX había iniciado su tercera modernización. Este proceso al ser interrumpido por el terremoto y la oleada migrante lo forzó a ingresar bruscamente en el mundo del desborde popular. La reconstrucción fue acompañada por el surgimiento lento del emprendimiento que con los años se ha vigorizado desde sus inicios informales hasta su relativo ajuste. La aparición de la universidad, la intensificación del turismo, las inversiones mineras y otros eventos han borrado la vieja ciudad y su mundo. Huaraz se ha convertido en un puerto terrestre adonde vienen a comprar y vender, tal como especuló al empezar el s. XIX, el viajero inglés William Stevenson que la visitó entre 1806 y $1808 .^{10}$

El otro espacio de los cambios se dio en el socio-cultural. Elementos rurales y agrestes migraron a la nueva ciudad: la q'eñua (polylepis), el saúco, la retama, el molle, el q'antu, el weshuru y otras especies de la flora autóctona antes relegadas y marginalizadas, se convirtieron en plantas decorativas de plazas, parques y jardines. Restaurantes, cafés, hostales, últimamente editoriales, instituciones educativas,

10 Yauri, M. 1993, El Señor de la Soledad de Huarás. Discurso de la abundancia y carencia. Resistencia andina. Lima, Edit. AVE, pp.21, 22

Yauri, M. 2014, "Huaraz, una historia fascinante", Ancash en el tapiz. Imágenes de su historia y cultura. Lima, ANR, pp. 63-78 
adoptaron nombres quechuas de cordilleras, glaciares, lagos, astros y maneras de llamar cariñosamente a personajes o ancianos del campo; en los restaurantes y cafés se empezó a usar vajilla producida por la artesanía popular y se cubrieron de decorados con elementos de la cultura indígena como también se introdujo las variadas formas de las viandas de la gastronomía nativa y popular La gastronomía cambió, se hizo extensiva con comidas nuevas producto de la imaginación, produciendo potajes mestizos e híbridos. Todo este retorno del pasado y su presentificación, significa el regreso de la vida que no fue vivida sino embalsada por 500 años. El panorama humano del Huaraz del pasado cambió. La introducción de música distinta ejecutada con instrumentos diferentes, los rituales en las fiestas religiosas, la elaboración de comida extranjera (italiana, francesa, tailandesa) borraron la imagen del Huaraz de antes del 70 . Hoy Huaraz es una ciudad semirrural, semiurbana, con intensa informalidad mercantil e hibridismos culturales, realidad sobre la que pesa la modernización, la presencia constante de turistas de todo estilo, con diferentes lenguas y de gente que está de paso, trabajadores de las minas de distintos lugares, hombres de negocios, etc. Esta ciudad nueva tiene una juventud inquieta que sueña con la literatura y la cultiva con discrepantes modos de expresión y pensamiento. Pues hay indigenistas o neoindigenistas conservadores que desean que el indio tradicional jamás cambie, otros que persisten con las historias de la guerra interna desatada por Sendero Luminoso o han introducido la novela negra, la ficción fantástica, o temas banales (crímenes pasionales, sexualidad, pandillaje juvenil, asaltos) características de una literatura que se produce para la distracción de una sociedad frívola. Estos son comportamientos extraños en un mundo donde la ebullición de los cambios sociales a nivel nacional repercuten y se añaden a los que se dan en la región y la localidad produciendo abundantes temas nuevos. En el plano lingüístico hay un conflicto: los padres de familia de las escuelas rurales advierten o suplican a los profesores a no transmitir los conocimientos a sus hijos en quechua, mientras que la universidad y los escritores -igual que el ministerio de educaciónexigen el cultivo del quechua y el uso de la educación bilingüe. Todo esto es un reencuentro y desencuentro que problematiza la vida y la cultura. Si lo descrito es positivo, el desborde ha producido, también, vertientes negativas. La informalidad golpea, igual la corrupción, el narcotráfico, la acción ilícita, cuyas expresiones son el caos que ha hecho presa en el Gobierno Regional, en las municipalidades, en las instituciones. ¿Podemos pensar que Huaraz es un mundo carnavalizado en términos bajtinianos? Huaraz ofrece; «...la percepción carnavalesca del mundo: el pathos de cambio y transformación, de muerte y renovación». Es como: «...la fiesta del tiempo que aniquila y renueva todo» ${ }^{11}$ Ha ocurrido un juego de negación

11 Bajtin, M. 1974, La cultura popular en la Edad Media y en el Renacimiento, Barcelona, Barral pp 175-176 
y afirmación sincrónicas además de la presencia de lo festivo y cotidiano y de un realismo grotesco, manifestación de: «los dos polos del cambio: el nuevo y el antiguo, lo que muere y lo que nace, el comienzo y el fin de la metamorfosis $\rangle^{12}$

Todo desborde es una ruptura que vence todo control. En términos de la naturaleza es un aluvión (lloclla, en quechua) que arrasa, destruye, aniquila, borra, mata sin que ninguna fuerza pueda controlarla o amortiguarla. Entonces, en el plano social, humano, cultural, político, etc. el desborde popular estudiado por José Matos Mar, al extenderse invade las cosas, los valores e ideas de la sociedad, produce acercamientos y rompimientos de todo aquello que está jerarquizado conjugando «lo sagrado con lo profano, lo alto con lo bajo, lo grande con lo miserable, lo sabio con lo estúpido» ${ }^{13}$ En la praxis ha producido el encuentro del Perú oficial con el Otro Perú, fenómeno que ha producido desacomodos, rupturas, conflictos, envejecimiento de mentalidades, todo esto que da lugar a una visión de un orden y un mundo que han entrado en crisis con visos de ser origen de cosas nuevas que pueden ser positivas y también negativas. Nos estamos debatiendo en este estado de cosas.

\section{EL PESO DEL PASADO}

Es evidente e innegable que estamos atravesados por la crisis. ¿Qué es la crisis? La crisis es la acumulación de tensiones en el cuerpo social que produce rupturas. En lo económico afecta los aspectos agrícolas y financieros, la actividad industrial y las fluctuaciones monetarias; al mismo tiempo que produce trastornos en lo político y en las mentalidades. Pero no perdamos de vista que la crisis no es sinónimo de decadencia. «En todo caso (...) siempre se debe tener en cuenta que en el interior de la crisis están presentes aspectos positivos o que la misma crisis en su conjunto puede estar vinculada a un proceso de consolidación $\rangle^{14} \mathrm{La}$ crisis que hoy sacude al Perú es una de renovación y crecimiento. Urge comprenderla para trazar estrategias que consoliden los cambios positivos y señalar los fenómenos negativos que pugnan por retrasarlos. La historia y la literatura son campos donde el pasado al imponer su presencia ha generado posiciones que no ayudan a una visión totalizadora tendente a la continuidad de las transformaciones. Tomemos el

12 Ob. cit. p. 28

13 Ob. cit. pp.173-174

14 Rosas M. F., "Crisis e historia: algunas consideraciones sobre la economía europea occidental en los s. XIV y XVII. Sociedad y cambio en Occidente, S. XI-XX, 2004. Lima, Universidad de Lima. pp. 117-119. 
tema de la literatura andina en la que hay tendencias disímiles. Unas optan por la pureza, otras por el mestizaje y la heterogeneidad. El analista Jorge Terán con un trabajo interesante nos acerca a tres novelas: 1) Rosa Cuchillo de Óscar Colchado que por su postura hermética, su resistencia cultural, produce una incomunicación total. La cosmovisión andina con la que el autor pretende representar el mundo andino, la novela se convierte en una postulación ideológica de rechazo cerrado a lo nuevo y moderno. La novela es la expresión de un etnocentrismo fundamentalista que al usar el mito opta por la inmovilidad histórica a la espera del mesías que haga realidad la utopía. 2) País de Jauja de Rivera Martínez donde palpita un mestizaje feliz, sin trabas, sin conflictos. Presenta o postula un mundo terso sin contrarios, donde no es posible sentir vergüenza de ser indio, mestizo o habitante de campo o ciudad, en una palabra la novela aspira a una síntesis de todo, ideal que se cristaliza en el protagonista Claudio que deviene en un ser en cuyo espíritu reina una orgía de lo universal, fenómeno deseable pero que linda con lo utópico, 3) Gran señor de Rosas Paravicino, un abanico de representaciones del mestizaje heterogéneo con distintos poderes sociales, económicos y culturales, que asumen posiciones contradictorias ${ }^{15}$ La novela trae de regreso la posición de Huamán Poma de Ayala: el mestizo es una casta impura, ambivalente, inútil, sin estabilidad emocional, en consecuencia sin identidad definida.

La literatura producida por algunos escritores al asumir una postura de resistencia no ha tramontado los límites del pasado. Los conceptos de utopía, mesianismo, milenarismo que la historia introdujo dentro del proceso del devenir del mundo andino y del país, los ha tomado como procesos aún no realizados, como hazañas épicas que el presente debe llevar a cabo. De ahí, por ejemplo, la eclosión de una poesía con tono de sufrimiento o de arenga como si no hubieran pasado los tiempos del Taki Onqoy, que aguarda el regreso de las huacas. No desea entender que esos movimientos importantes ya cumplieron su papel en el proceso de nuestra historia. Igual, gran parte de la producción novelística persiste representando al mundo andino como una sociedad cerrada, sin cambios, es decir ahistórica, lo que le ha conducido a asumir el tema con un estilo que lo acerca a la corriente del Andinismo que es una réplica del Orientalismo que los científicos sociales europeos han creado, considerando al Oriente como el mundo hermético, estancado, distinto (el Otro) a Europa. Esta literatura no internaliza los cambios y problemas que ha traído el desborde popular y la continua transformación social que la historia

15 Terán, J. "Grupos socio-culturales en la narrativa andina peruana contemporánea: del hermetismo resistente a la orgia universal. Ilymen. Cultura y literatura, 2005 Lima, No 3 pp 111-134 
señala. Continúa viendo al indígena como en los tiempos de antes de la reforma agraria y en un grado extremo practicando ritos seculares o pensando míticamente. El campesino (exindígena) igual que cualquier sujeto ha sido impactado por la electrónica: usa dispositivos electrónicos, en una palabra, el mundo andino, de la oralidad hace tiempo ha ingresado a la escribalidad y de esta, hoy, a lo electronal, en consecuencia su imaginario y mentalidad han sufrido cambios. La mayoría campesina en las fiestas practica los rituales tradicionales por costumbre, no porque sabe sus significados. En la realidad siempre ha carecido de información histórica. Inclusive es innegable que lo que conoce la intelectualidad de la ciudad letrada, en este aspecto, es la consecuencia de la difusión que han llevado a cabo algunos profesionales de las ciencias sociales. Un caso es preeminente. El del escritor José María Arguedas. Al estudiar su obra los analistas han incidido exageradamente en la condición de niño que al ser marginado vivió su infancia entre indígenas, que aprendió el castellano a los 11 años; en otras palabras, han enfatizado la escisión que hizo de él un ser espiritual, social y culturalmente troceado (como Inkarrí), permanentemente asociado a la tragedia y al dolor. ${ }^{16}$ Esta estrategia ha sumido a su obra en un limbo. Su producción ha sido antropologizada, etnologizada, sociologizada, sicoanalizada, ideologizada hasta el exceso. Es impostergable su rescate como producto literario, tarea que significa replantear las perspectivas y encontrar «la senda perdida», para ir al encuentro de sus novelas y poemas que por culpa de sus estudiosos no nos entrega esa manera de vivir del autor poéticamente el mundo y la vida, como quería Hölderlin, ese deseo de capturar poéticamente el mundo como una totalidad por el camino de la «santa prostitución del alma», tópico que dejaron entrever Roman Jakobson y Lévi-Strauss en el análisis de «Los chats» de Charles Baudelaire.

Asimismo, no es lo deseable el comportamiento de los críticos y de los estudiosos de la literatura peruana. En ellos campean por lo menos dos gestos. Primero, basta que un autor sea del interior del país para ser calificado, sin que nada ni nadie lo salve, de indigenista; esta caracterización le es negativa al escritor: se le cierran las posibilidades de la difusión a nivel de lectoría y del ambiente académico. El segundo es que los escritores de provincia por lo común no son aludidos ni citados en el mundo académico, aun cuando su producción es reconocida por su valor en el ambiente académico extranjero; los mismos estudiosos que fungen de partidarios de la pluralidad cultural cultivan sus simpatías y antipatías; el

16 Edmundo Bendezú A. recientemente nos ha ofrecido un libro con título de esa naturaleza: Ama wakashpalla. José María Arguedas. 2014, Lima, Universidad Ricardo Palma. ¿Por qué asociarlo al llanto? 
resultado es que algunas obras son promocionadas y otras silenciadas a pesar de que cualitativamente son superiores. ¿Por qué el escritor calificado de indigenista es marginado? Subsiste, a pesar de los esfuerzos, la idea de que los Andes y el indígena corresponden al mundo incivil. Este pensamiento tiene su expresión cumbre en los filmes Madeinusa y Teta asustada. En el primero, el ficticio pueblo de Manayaycuna, se debate en la suciedad real y moral, el alcoholismo, el desorden, la violencia cotidiana, hasta el incesto que recrudece en el Tiempo Santo de la Semana Santa. Situado en una naturaleza de horizontes desmesurados y vacíos, es expresión de un espacio donde campea la naturaleza y no la historia, en otras palabras la incivilidad y barbarie. Todo esto y mucho más -según el filme- afecta a la sociedad quechua e indígena. La ideología que campea en Madeinusa se repite en La teta asustada. Ambas son la representación de los Andes ahistóricos, es decir de la sierra peruana que según piensa el sector criollo, se ha quedado fuera de la historia, congelada en la brutalidad, el salvajismo e incivilidad. Manayaycuna es una palabra quechua envilecida, expresa la imposibilidad de escapar de la barbarie que tiene visos de eternidad; igual en La teta asustada, al mundo andino se le ha "colgado" algo que jamás ningún ritual usa; ni mito, ni leyenda o cuento mencionan: el tubérculo insertado en la intimidad de la mujer. ${ }^{17}$

\section{CAMINOS QUE SE BIFURCAN}

Los textos que al empezar hemos mencionado nos enriquecen con sus reflexiones. Son sobre tópicos nacidos en escenarios de ruptura donde se ha dado el encuentro asimétrico de culturas diferentes. Todo encuentro cultural produce tensiones y conflictos a veces traumáticos que se prolongan por largo tiempo. Nos aproximan a circunstancias que por ser desconocidas nos hacen soñar, por ejemplo, con un mundo terso de los tiempos antes de la colonia. Jorge Bernuy en Escritura quechua en el Perú, nos hace saber que la poesía quechua tuvo su reconocimiento fuera del Perú y por extranjeros. Asimismo que su evolución ha pasado por lo menos por tres etapas: la misionera del s. XVII, la señorial indigenista en el s. XIX y la migrante. Al principio por ser obra de criollos y mestizos vinculados a la aristocracia cusqueña careció de identidad, pero que contribuyó al surgimiento del nacionalismo inca del s. XVIII. En el s. XIX el discurso indígena careció de voz propia, fue la de quienes se apropiaron de ella para soñar con el pasado; en el XX fue labor de mestizos urbanos, de la clase media o sectores aristocráticos

17 Ver, Terán M. Jorje: «Andinismo y Madeinusa: la pervivencia». Revista Académica UNASAM (Universidad Nacional de Ancash Santiago Antúnez de Mayolo, Huaraz, No3, 2015, pp.271-302 
provincianos caídos en pobreza. Su discurso es heterogéneo, señorial, mítico y pierde relación con lo indígena. El discurso de los migrantes tiene propósitos de acuerdo a como son: integrados, marginales o submarginales, con tono de composición y recomposición, para reintegrarse a lo mítico y la utopía andina. ${ }^{18}$ Elegía Apu Inka Atawalpaman, libro de Odi Gonzáles, es la historia de ese poema que él reconoce como el primer documento de la resistencia incaica. Lo interesante en cuanto a su autor es la hipótesis que formula en el sentido de quien lo pudo haber escrito fue el P. Blas Varela, víctima de la política antiindígena colonial. Expulsado en Lima por su orden jesuítica por supuestos pecados, fue exiliado a España donde fue prisionero en Cádiz. Víctima de venganzas por su posición semejante a la de Bartolomé de las Casas, se le exigió renunciar a su orden o fingir su muerte. Declaró su muerte. Al reaparecer clandestinamente en el Cusco, en su refugio habría escrito además de la Elegía, la Nueva Crónica y buen gobierno. ${ }^{19}$ Poéticas afroindoamericanas de Carolina Ortiz es un interesante estudio de la cosmovisión /episteme que encierran los discursos nativos de los pueblos subyugados en los procesos coloniales que subsisten en una diversidad de lenguajes. Lo relevante de esas poéticas es que a partir de Dioses y hombres de Huarochiri, Nueva crónica y buen gobierno, encierran estructuras sociales en las que la mujer ha vivido bajo una sombra patriarcal y donde juegan fuerzas de seducción y apropiación del cuerpo en un proceso de la colonialidad del poder. En Literaturas regionales: narrativa huaracina reciente. Terán Morvelli, estudia la producción de escritores jóvenes de la región a partir de una óptica que engloba las diversas formas del neoindigenismo. ¡Soi indio! es un conjunto de estudios sobre la poesía de Efraín Miranda que optan por una línea de reflexión teñida de una alta emoción andina. El volumen: Augusto Higa, producido por un grupo de críticos encabezados por J. Terán y Edith Pérez Orozco, es dentro del conjunto de estudios de la cultura de las minorías étnicas como el libro de C. Ortiz, un enfoque de la literatura de la identidad nisei peruanojaponés. Este libro cuyo núcleo es el estudio del desgarramiento del yo en un país y una cultura diferentes, mueve a pensar que también es urgente conocer la tragedia que viven los migrantes peruanos, sean criollos o andinos, aquí o en el extranjero. El desgarramiento que causa el desarraigo incita a pensar que hoy, la literatura debe tender a la opción de crear en medio de la intersección con el Otro. Los migrantes de todo tiempo y lugar, de toda raza y cultura son sujetos de distintos estamentos

18 Bernuy, J. «Poesía quechua: las múltiples voces de la letra». Escritura quechua en el Perú, 2011 Lima, Pakarina Ediciones, pp. 63-95

19 Esta hipótesis de la historiadora italiana Laura Laurencich Minelli basada en unos documentos hallados en Nápoles de los que es propietaria, no ha sido probada. Desató muchos comentarios en las que fue involucrada inclusive la especialista en Huamán Poma de Ayala, Rolena Adorno. 
sociales. El impacto del desarraigo no hace diferentes a los unos y los otros. Esta característica se advierte por ejemplo en varias novelas de Alfredo Bryce Echenique y del novelista poco difundido, Rafael Moreno Casarrubios. En ambos casos los protagonistas no son andinos, ni campesinos, ni pobres, sino limeños de clase media de Miraflores y viven experiencias no gratas en Europa y Australia. Narrativa de la víctima de Douglas Rubio Bautista, revela el abordaje monográfico del nacimiento de la literatura urbana con la obra de Enrique Congrains.

Esta pequeña muestra visibiliza la reacción ante la globalización de los espacios periféricos, marginales y de frontera. Allí donde el yo colectivo pierde su pivote y cae a una incapacidad para identificarse, el mundo se le presenta fragmentado. Para darle sentido a la nueva realidad opta por la resistencia y se desencadena procesos de integración a nivel local, regional, zonal, nacional y de minorías étnicas. Las historias se desconectan, salen a campear «las metodologías fragmentacionistas» que limitan y comprometen el análisis histórico ${ }^{20}$ Este fragmentacionismo caracteriza a gran parte de los estudios culturales del país. El nacionalismo que les caracteriza se repliega en el pasado donde encuentra base para sus especulaciones teñidas de mesianismo y utopismo.

Aquí es donde el camino de la búsqueda de la integración se bifurca y sus ramales siguen bifurcándose. Creyendo resistir a la acción homogeneizadora de la globalización, los estudios fragmentan los temas. La herramienta de la alteridad usada no en términos de integración sino dentro de la diferencia del uno/otro ha contribuido a crear distancias en el interior mismo de nuestra realidad lo que ha servido para justificar los errores del uno y del otro y crear intersticios de impunidad. Occidente, ante este escenario continúa con su visión dieciochesca del que se ha servido el realismo maravilloso que ha proyectado la imagen del Perú y de América Latina como un mundo sumido en la penumbra de un primitivismo feliz atravesado por pulsiones de violencia, que usada políticamente le sirve para vernos como un espacio estancado y exótico donde nada cambia pero que es útil para sus inversiones y el lavado del estrés mediante el turismo. A este deseo occidental responden algunos devotos del neoindigenismo o de lo andino creando una literatura que nos presenta al país y al indígena del pasado pensando conservadoramente que nada ha cambiado. Literatura que no quiere convencerse que ese indígena del desborde

20 Esta reflexión pertenece al concepto de las «historias conectadas» que postula el historiador Fernando Rosas Moscoso en: Perú Europa: dos casos de historias conectadas, 2009, Lima, Universidad Ricardo Palma. Él dice: «...lo que pueda ocurrir tanto en Potosí como en Paita tiene relación no solo con el contexto espacial inmediato sino también con el espacio suprarregional peruano, americano y mundial» p. 10 
popular o sus descendientes ahora son el empresario, el importador y exportador, el político; el sujeto que ha accedido al congreso, al profesionalismo, a la universidad, inclusive a la presidencia. Que igualmente son los microempresarios, por ejemplo de Lima Norte que se miden casi a duelo con los megamercados. Este fenómeno que sumado a otros entre ellos el sentido de la identidad, la distinción y el consumo en los microempresarios hacen vacilar los viejos conceptos de la identidad y de la cultura nacional. El concepto de cultura nacional no debe ser ambiguo como en la década de los ochenta, sino debe unir a todos, a los urbanos y mestizos, a la costa y a la sierra. La migración, tal como afirma Pedro Jacinto Pazos, ha cambiado y continúa cambiando a la capital. «Lima ya no tiene un coto cerrado para un determinado grupo de personas, ya no presenta al migrante como un enemigo menos a los hijos de este» (2015: 239) Todo encuentro de culturas genera un juego de imaginarios cuyo resultado es nuevo y enriquecedor. En el caso peruano la cultura andina, la mestiza, la de la costa y de la sierra, la rural y urbana hoy consideran a la ciudad capital, Lima, como: «la ciudad de todos los peruanos» así como: «La catedral de Lima es la representación de la tradición religiosa de todos los peruanos» donde además, la Plaza de Armas, la Plaza San Martín, y las que tienen los nombres de los héroes de Grau y Bolognesi son los íconos de la nación (Ibíd. 239, 241) La vieja visión no quiere saber de la transformación de la capital del país, donde ahora la nueva sociedad peruana tiene otro rostro y otras formas de trabajar, vivir y soñar, tiene otras aspiraciones y proyectos que son un reto; que de igual manera, deliberadamente ignora -o mira al sesgo- que la meta del mundo andino es seguir conquistando la ciudad acorde al movimiento mundial. ${ }^{21}$ El historiador Fernando Rosas Moscoso escribe: «...no se debe dejar de lado el nuevo mensaje del mundo andino, un mensaje que se plasma en las características de nuestra nueva sociedad. Conquista del espacio urbano - antigua punta de lanza de lo occidental-conquista en el terreno de las expresiones culturales y en el plano de lo político. Todo esto porque el mundo andino no solo está vivo y vigente, sino está recreándose, porque pese a muchas muertes que significaría que somos una nación inacabada, un signo está fuera de duda, la Permanencia. (Rosas M: 2009, 42)

A su vez el mundo criollo sigue alimentando el desencuentro de ayer. Este desencuentro estalló en una furiosa polémica entre escritores andinos y metropolitanos en el 2005, en Madrid. Polémica intrascendente, más bien grotesca por la postura que cada grupo adoptó considerándose genial y representante real de la literatura peruana. Hoy, a la distancia de 11 años el escritor Fernando Ampuero

21 Según el urbanista Angus Laurie la población mundial en el 2050 será urbana en un promedio del $75 \%$. En lo referente al Perú dice: "Nuestro país es altamente urbanizado, con el $76 \%$ de la población viviendo en ciudades". El comercio, Lima, domingo 10 de abril del 2016, p.12 
dice: «...la literatura andina está de muy capa caída», en tanto que la criolla se reconoce Generación Post, de espíritu centralista por ser: «primordialmente limeña, cosmopolita, tiene su público, incluye a peruanos con repercusión internacional y contradiciendo las críticas virtuales y anónimas que la tachan de ser un invento de las editoras transnacionales, parece inamovible» ${ }^{22}$ Estas y otras actitudes reproducen asombrosamente. hoy, en la primera década del s. XXI: «...la sociedad peruana colonial (...) dividida en dos sectores o subsociedades, o las que en la terminología de la época se denominaba "república de españoles" y "república de indios" ${ }^{23}$ ¿Acaso esta manera de actuar y pensar de los peruanos en el siglo XXI es un muro como el de Berlín (hoy destruido), que cada quien cuida que no se desplome porque si se desploma no va a tener tema para sus discursos? Este narcicismo que cada grupo alimenta debe desaparecer. Toda cultura es fruto de procesos transculturales. El mundo es un archipiélago de semiosferas culturales. Existen similitudes y diferencias, semejanzas, calcos, imitación, reproducciones sin fin. El caso de Huamán Poma de Ayala, es semejante al del molinero Menocchio de El queso y los gusanos de Carlo Ginzburg. Cada uno con su respectiva cosmovisión producto de lecturas de textos diversos en escenarios de culturas y sociedades dominadas y dominantes. Igual el regreso de las huacas o de Inkarrí, es semejante al regreso mítico del nacionalista Parnell, el líder irlandés de la independencia. El Wiracocha que recorre el mundo creando seres humanos y vida natural, repartiendo funciones, es en la mitología medieval de Europa el Jesús caminante que pone a prueba la bondad de la gente, castiga a los malos sumiéndolos en la sima de lagos con aldea y todo. El tiempo circular que se nos dijo era concepto andino, es universal, es el mito del eterno retorno, desde la Odisea hasta la especulación poético-filosófica de Los siete sellos (Así habló Zaratustra) de Nietzsche. Este mismo filósofo asevera que la vida y la historia se sirven mutuamente. Lo «ahistórico» y lo «histórico» son necesarios para el buen vivir de los individuos, pueblos, colectividades, la

22 Ampuero, Fernando, «Generación Post», El Dominical de El Comercio, Lima, domingo 10 de agosto, 2015, p. 17. Los dos grupos hablan orgullosamente de la internacionalización de sus obras. Pero la internacionalización a la que se refieren radica en los protagonistas de sus producciones que son migrantes, y no en el mercado de lectores en el exterior. Esta internacionalización que cada grupo sueña, para su desengaño, no es sino una apropiación imaginaria de los espacios físicos extranjeros, fenómeno que se dio hace siglos comenzando con Homero. En la literatura peruana Cinco metros de poemas de Carlos Oquendo de Amat., es un bello ejemplo. Hoy, con la imaginación no solo se migra a espacios terráqueos extranjeros, sino a otros planetas, como el caso del narrador boliviano Edmundo Paz Soldán, con su novela Iris.

23 García Bedoya, Carlos: «Discurso criollo y discurso andino en la literatura peruana colonial» Indagaciones heterogéneas. Estudios sobre literatura y cultura, 2012, Grupo Pakarina SAC, Lima. pp.165-166 
cultura. Lo «ahistórico» es la capacidad de olvidar, lo histórico es la prescindencia de esa capacidad. Una postura histórica excesiva es dañina para la vida. Desde este punto de vista todo pueblo debe aprender a servirse de la historia. ¿Cómo, de qué manera? Ejerciendo la capacidad de pensar y usar la historia críticamente. ${ }^{24}$ Es decir como muerte y resurrección, con proyecto donde el futuro decida si el pasado está muerto o vivo. En nuestro caso debemos dejar de recordar obsesivamente nuestros traumas. Por ejemplo de cómo fuimos victimizados con la conquista, el coloniaje, los caudillismos y militarismos, de cómo las mayorías fueron dominadas y olvidadas desde 1821. Esta memoria lastimada (Paul Ricoeur) presentificada con obsesión, a veces de modo casi masoquista, por poetas, novelistas y profesionales de las ciencias sociales contribuye a no avanzar en el camino; en otros casos, con el añadido de la alteridad, sirve para justificar nuestros errores, nuestras debilidades, e informalidades, nuestras deficiencias. Nutre las utopías, los mesianismos que nos sumen en esperanzas inviables o en la sombra del árbol de los muertos heideggeriano haciéndonos perder el carro de la historia. ${ }^{25}$ Necesitamos cicatrizar las heridas, eliminar o acortar las distancias para propiciar las intersecciones con los otros y crear en esos espacios un permanente diálogo creador con seres dialogantes para fundar la unidad del ser histórico que recuerde lo que se fue y tenga conciencia del futuro. Necesitamos vencer el peso del pasado lastimado y traumatizante como en la novela Hermano y hermana, de Rainer María Rilke, voz de la Belle Époque que se desvaneció con el trueno de la primera guerra mundial. En esta novela, en el viejo mundo pragués, primero muere el hermano, luego la madre, los dos aniquilados por el peso de la nostalgia del pasado. Pero antes, la hermana viaja a la llameante montaña de la fiebre y regresa curada; sobrevive a las dos muertes y llega la primavera. Convertida en profesora de piano ve que el mundo se le abre y se siente feliz. Al inquilino de su departamento, un joven triste y solitario, también víctima de la añoranza, le incita a salir y gozar de la primavera. Llega el amor. Con él el milagro de la nueva vida.

24 El poeta holandés, candidato al Nobel de Literatura Cees Nooteboom que ha vivido en la segunda guerra mundial una y mil muertes, dice: «Si uno tuviese que acordarse de todo, reventaría. (...) El olvido es una medicina que se debe beber a tiempo»

25 En la historia inmediata de nuestro país hay dos expresiones con connotación utópica y mesiánica: «El chinito de la esquina va a derrotar al doctor Vargas Llosa» El "chinito" era el supuesto Mesías, el hombre del pueblo marginal y pobre que salvaría al Perú. El gobierno del "chinito" significó la peor de las desgracias que dejó al Perú desmantelado, pobre y herido. Otra expresión fue: «Cholo sano y sagrado». Ese cholo accedió a la representación de la huaca que retornaba para restaurar el orden en un país viciado después del gobierno de un dictador. Pero desafortunadamente esa huaca estaba educada, instruida, entrenada en el corazón del poder imperial. El gobierno de cada uno ha significado para la historia nacional no solo olvido del origen sino también engaño, mentira, traición, frustración. 


\section{REFERENCIAS BIBLIOGRÁFICAS}

Aubes, F. (2004). «La novela de Atusparia o cómo la memoria de las luchas andinas ingresa a la literatura» Lhymen. Cultura y literatura No 4, Lima, 2004 pp.117-125.

Bernuy. J. (2011). Escritura quechua en el Perú, Lima: Pakarina Ediciones.

García Bedoya, C, (2012). Indagaciones heterogéneas. Lima: Grupo Pakarina.

Hopkins, E. (2015). Solo literatura. Estudios. Lima: Universidad Ricardo Palma.

Jacinto Pazos, P. (2014). Micronegocios vs. megamercados: otros estudios de identidad, distinción y comercio en los microempresarios de Lima Norte. Lima: Universidad Nacional Mayor de San Marcos.

Mariátegui, J. C. (1974). Siete ensayos de interpretación de la realidad peruana, Lima: Biblioteca Amauta.

Matos Mar, J. (1984). Desborde popular y crisis del estado. El nuevo rostro del Perú en la década de 1980. Lima: Instituto de Estudios Peruanos.

Matos Mar, J. (2012). Perú. Estado desbordado sociedad nacional emergente. Lima: Universidad Ricardo Palma.

Merino, R. (2004). «Lo que Dios unió que no lo desuna el hombre. La representación como vínculo primordial entre el poder y el conocimiento. Lima: Lhymen, cultura y literatura No 4, pp. 27-48

Rosas Moscoso, Fernando, (2009). Perú y Europa: Dos casos de historias conectadas (Siglos XVI y XVIII), Lima: Universidad Ricardo Palma.

Terán M. J. (2005). «Grupos socio-culturales en la novela andina peruana contemporánea: del hermetismo resistente a la orgía universal. Lima: Lhymen. Cultura y literatura No 3, pp. 111-134-

Ward, T. (2004). La resistencia cultural. La nación en el ensayo de las Américas. Lima: Universidad Ricardo Palma. 
Yauri Montero, M. (2005). «La crítica literaria, hoy» Revista de la Facultad de Lenguas Modernas. Lima, Universidad Ricardo Palma: pp. 1-17

Yauri M. (2006). Laberintos de la memoria. Lima: Fondo Editorial del Pedagógico San Marcos, Instituto de Ciencias y Humanidades. 